\title{
Convection Heat Transfer Analysis with Flow Resistance for Mini-Helically Coiled Tubes at Supercritical Pressures Experimentally
}

\author{
Ameer Abed Jaddoa \\ Electromechanical Engineering Department, University of Technology, Baghdad 0096, Iraq
}

Corresponding Author Email: ameer.a.jaddoa@uotechnology.edu.iq

https://doi.org/10.18280/ijht.390315

Received: 23 April 2021

Accepted: 25 May 2021

Keywords:
supercritical $\mathrm{CO}_{2}$, helically coiled tube,
exergy destruction, friction factor and
pressure drop

\section{Keywords:}

exergy destruction, friction factor and pressure drop

\begin{abstract}
This paper analyzes the effect of fluid flow characteristics on the convection heat transfer for mini-helically coiled tubes (HCT) using supercritical carbon dioxide $\left(\mathrm{CO}_{2}\right)$ as a natural refrigerant. Two experimental cases have studied in this work for mini-helically coiled tubes at different diameters with different coil pitches for analyzing the convection heat transfer with flow resistance. In the first case, the inner tube diameter, coil diameter and coil pitch were $5 \mathrm{~mm}, 200 \mathrm{~mm}$ and $10 \mathrm{~mm}$ respectively, while $10 \mathrm{~mm}, 100 \mathrm{~mm}$ and $5 \mathrm{~mm}$ were for the second case. Moreover, this work has also investigated the influence of frictional pressure drop, heat flux, friction factor and mass flux on dimensionless exergy destruction. The work environments were $300-500 \mathrm{~K}$ as an inlet temperatures range, 200$2000 \mathrm{Kg} /\left(\mathrm{m}^{2} . \mathrm{s}\right)$ as a mass heat fluxes range, 50,000-500,000 as a Reynolds number (Re) range and $50-200 \mathrm{Kw} / \mathrm{m}^{2}$ as an inner heat fluxes range. As a result, a large effect has been observed for dimensionless exergy destruction compared with the flow friction of $\mathrm{CO}_{2}$ which induced by heat transfer irreversibility. On the other point of view, a good sensitivity of optimal Re with the tube dimeter and mass flux also noticed compared with the heat flux. At a suitable range for Re, smallest and best exergy destruction also noticed for the tube diameters. A correlation has for the optimal Reynolds number as function of main dimensionless parameters related to wall heat flux, mass flux, fluid properties and geometric dimensions is proposed. Characteristics of the fluid flow had influenced significantly by mass and heat fluxes. In the future, the collected experimental data can be employed in order to design and improve the refrigeration conditioning performance for exchangers and other systems such as heat pumps.
\end{abstract}

\section{INTRODUCTION}

Characteristics of supercritical $\mathrm{CO}_{2}\left(\mathrm{SC}-\mathrm{CO}_{2}\right)$ as a working fluid has attracted the attention of researchers in many industrial applications due to its a natural material, Global Warming and Ozone Depletion Potentials equal to one and zero respectively, friend to the environment, non-toxic and non-flammable as well as it has low pressure and temperature than the water relatively. There are many famous systems used $\mathrm{SC}-\mathrm{CO}_{2}$, combined systems and Organic Rankine cycle [1, 2]. Also, recent industry production has used $\mathrm{SC}-\mathrm{CO}_{2}$ in addition to it could solve the dangerous production processes on the environment that increased nowadays [3]. On various kinds of cotton fabrics, $\mathrm{SC}-\mathrm{CO}_{2}$ has utilized in impregnation process by ammonium palmitate. The aim of work is to prove the effect of water-repellent, in addition to present ability of the modified and pure $\mathrm{SC}-\mathrm{CO}_{2}$ to dissolve the ammonium palmitate [4, 5]. Jaddoa [6], studied experimentally the convection heat transfer for mini-tubes with fins in the presence of $\mathrm{SC}-\mathrm{CO}_{2}$ media. The study included effect of many parameters on the convection heat transfer such as, inlet temperature, friction factor, mass flow rate, heat flux, performance evaluation criteria, enhancement efficiency and Nusselt number. In air-conditioning systems (heat pump), mini-tube as a helical coiled with $\mathrm{SC}-\mathrm{CO}_{2}$ has employed widely in order to recover the low-grade waste heat [7]. The reason behind that is superior the HCT performance compared with straight one in addition to its embedded structure. Thus, in heat exchangers design, its necessary to study the characteristics of heat transfer for $\mathrm{HCT}$ s with $\mathrm{SC}-\mathrm{CO}_{2}$ media. Wang et al. [8] employed the $\mathrm{SC}-\mathrm{CO}_{2}$ for $\mathrm{HTC}$ media experimentally in order to investigate the characteristics of flow. The results showed that the there is a little bit difference between frictional pressure drop for $\mathrm{SC}-\mathrm{CO}_{2}$ and single-phase water. Where, in the beginning, it decreased with the mass flux then increased. Another contribution was made by Xu et al. [9] to cool the heat transfer experimentally using $\mathrm{SC}-\mathrm{CO}_{2}$ for HCT when the wall heat flux was constant. The results analyzed according to exergy, and they reached out the optimal Re and dimensionless exergy destruction. Using simulation methods, many pervious works have been done to study the behavior of heat transfer for straight tubes with SC-CO 2 [10-12]. Moreover, turbulent Prandtl has no significant effect on the heat transfer. Two shapes of tubes have proposed by Cao et al. [13] one was circular and the other was triangle in horizontal position to investigate the laminar heat transfer of $\mathrm{SC}-\mathrm{CO}_{2}$ numerically through analyzing the buoyancy and fluid physical properties influence. The results showed influence of the buoyancy in heat transfer enhancement. Another study dealt with the effect of the buoyancy on the heat transfer of $\mathrm{SC}-\mathrm{CO}_{2}$ numerically [14]. The results predicted the low Reynolds turbulence number of $\mathrm{k}-\varepsilon$ model and $\mathrm{V} 2 \mathrm{~F}$ types. In addition, they recommended that the buoyancy influence could be significant on heat transfer of SC-CO 2 . $\mathrm{Li}$ and $\mathrm{Lu}$ [15] used $\mathrm{SC}-\mathrm{CO}_{2} / \mathrm{R} 41$ 
to cool the heat transfer experimentally. The outcomes revealed that the relationship between HTC and the composition of R41 was opposite, where if HTC is increased, the composition of R41 will decease and vis-versa at pseudocritical temperature (Tpc) zone. At the same region, HTC also decreases with qw increasing, but the HTC will be influenced a little by qw if bulk temperature $(\mathrm{Tb})$ be far from $\mathrm{T}_{\mathrm{pc}}$. Mixed SC- $\mathrm{CO}_{2}$ and ethane as a working fluid has been proposed by Kravanja et al. [16] for cooling the heat transfer through a coiled pipe. One of the important conclusions was the mixture's higher efficiency in cooling the system compared to pure coolants. Based on previous research, it was found that the use of coiled pipe is more preferable than straight pipe, and the reason is attributed to the fact that the liquid flowing in the coiled tubes is subjected to centrifugal force, which leads to secondary flows, thus increasing additional heat transfer and lower pressure during the cross section of the pipe [17]. AbdelMoneim and Ali [18] evaluated and improved the heat transfer performance by generating the entropy and the percentage exergy destruction rate inside tubes. To obtain the optimal geometry of duct, Şahin [19] employed irreversibility under laminar flows with constant heat flux. The main problem that faced the designers of heat exchanger was the process of improving heat transfer was accompanied by a decrease in pressure. Therefore, it was required to find a balance between heat transfer and pressure drop through friction loss in addition to reducing reflection in the thermal system and better use of available energy. One solution has been proposed to improve the thermal system by reducing the entropy to a minimum, whose increase leads to the emergence of thermodynamic irreversibility in terms of heat transfer and fluid flow [20]. Therefore, in this work it is suggested to use HCT in order to prevent energy destruction and generation of entropy (irreversibility) due to heat transfer. Experimental investigation of heat transfer features for vertical tube using porous media and Carbon dioxide was studded [21] the results appeared that the lower pseudocritical temperature $\left(\mathrm{T}_{\mathrm{pc}}\right)$, than the inlet temperature $\left(T_{o}\right)$ leads to reduce the coefficient of heat transfer compared with the case of the pseudocritical temperature value higher than the inlet temperatures.

In this work the heat transfer of $\mathrm{SC}-\mathrm{CO}_{2}$ to a $\mathrm{HCT}$ was experimentally verified by exergy analysis. Where, in this research an analysis of the effective parameters that affect the external energy destruction was conducted in order to obtain the best design of the HCT with the best use of the available energy. In addition, the flow characteristics of $\mathrm{CO}_{2}$ inside the HCT were also verified under uniform wall heat fluxes.

\section{EXPERIMENTAL SETUP AND INTEGRATED DEVICES}

This paper relates with studying the characteristics of SC$\mathrm{CO}_{2}$ convection heat transfer for mini-tubes experimentally. Figure 1 show the schematic for the system, test section and actual experimental design. The experimental rig consisted of cylinder that used to provide the compressed $\mathrm{CO}_{2}$, of system included a compressed $\mathrm{CO}_{2}$ container, thermo-compressor, magnetic pump, portable chiller with cooling water bath, digital multimeter model KL-635 0C to measure the current, flowmeter type Coriolis model ALMNSO2345, manometer, data acquisition system model HS 267A to measure the voltages that crossing through test section and electrical heater, pressure gage model KLMN687T and differential pressure gage model AKLM200C, input-output electrical power measurement system and heater. Two HCT used in this work to investigated the convection heat transfer with different inner diameters (5 and $10 \mathrm{~mm}$ ), different coil diameters (200 and $100 \mathrm{~mm})$ and different coil pitches (10 and $5 \mathrm{~mm})$. polytetrafluoroethylene ethylene (PTFE) layer has used for thermally and electrically insulating and locates between screws and the flanges. To heat the HCT, an electrical resistance wire has used and wrapped around it. Voltages, currents and resistance used to calculate the input electrical power for heater. Other parameters have experimentally measured such as" voltages of heater, pressure drop flow rate, pressure and temperature inlets, outlet and wall temperatures and electrical resistance". 15 thermocouples made form copper-constantan used in this work to measure the local tube temperature and fixed by welding on the outer surface of the HCT in depth and width of $2 \mathrm{~mm}$ along the tube. An accurate thermal resistor used to Measure of inlet and outlet temperature after mixing the fluid before and after test section by mixers. All thermal measurement devices have been calibrated before using to obtain an accurate reading according to oil bath constant temperature with accuracy of $\pm 0.3^{\circ} \mathrm{C}$. on the other hand, many transducers have employed to measure pressure. One is the pressure gage model KLMN687T to measure the inlet pressure, and the other is differential pressure model KLM200C to measure the pressure drop. The full range and accuracy for both transduce were $15 \mathrm{MPa}, 0.04 \%$ and $800 \mathrm{KPa}, 0.09 \%$ respectively, in order to build a sufficient imagination, mass flow rate has conducted. The accuracy of flowmeter was $0.4 \%$ and ranged from $0-100 \mathrm{~kg} / \mathrm{h}$ of nominal reading. Different processes implemented before the experimental work. One of these was evacuate the test loop by vacuum pump, and the other was washed in the test loop by $\mathrm{CO}_{2}$ with a high purity of $99.9 \%$ from 6 to 8 times. To make the pressure inside the test loop steady at $5 \mathrm{MPa}$ up to $10 \mathrm{MPa}$, Thermo-compressor used to feed the container and then to the test loop by $\mathrm{CO}_{2}$ which is increased gradually. The compressed $\mathrm{CO}_{2}$ remained inside it by closing the valve, and super-critical magnetic pump used to circulate $\mathrm{CO}_{2}$ at $\mathrm{SC}$ pressure. The test loop was tested to notice the leakage which was very small at high pressure. Moreover, silicate glass fiber and sponges used to insulate the test loop. inlet fluid temperature, mass flow rate and input power were measured at each test by connecting the measurement instruments to the personal computer by data acquisition system (HS 3986T). When the system reached to the steady state conditions, pressure drop, inlet pressure, mass flow rate and temperatures have monitored in addition to record the electrical voltage and current for heater. The term of local bulk indicates to calculate the fluid temperature at each measuring section according to the input power, mass flow rate and inlet to outlet temperatures. The heat balance uncertainty for experiments was $\pm 6 \%$. The system reaches to the steady state condition after 40 to 160 mins, in spite of this, changes in flow rate, temperature and inlet pressure were monitored during the initial transition. The acceptable limit of temperature variations for inlet and outlet, and wall temperature within $\pm 0.1{ }^{\circ} \mathrm{C}$ at steady state condition, while the acceptable limit of inlet pressure and flow rater variations within $\pm 0.2 \%$ in same condition (steady for 10 mins at least). The main reason for being the heat transfer coefficients by convection is experimentally uncertain is due to errors in the heat transfer surface temperature calculation, errors in the measurement of temperatures in addition to the experimental errors in the temperature balance and the axial 
thermal conductivity. The experimental uncertainty has been estimating by the root-mean square for convection heat transfer coefficient and inlet pressures which were equal to $11.3 \%$ and $\pm 0.09 \%$ for the HCT respectively.

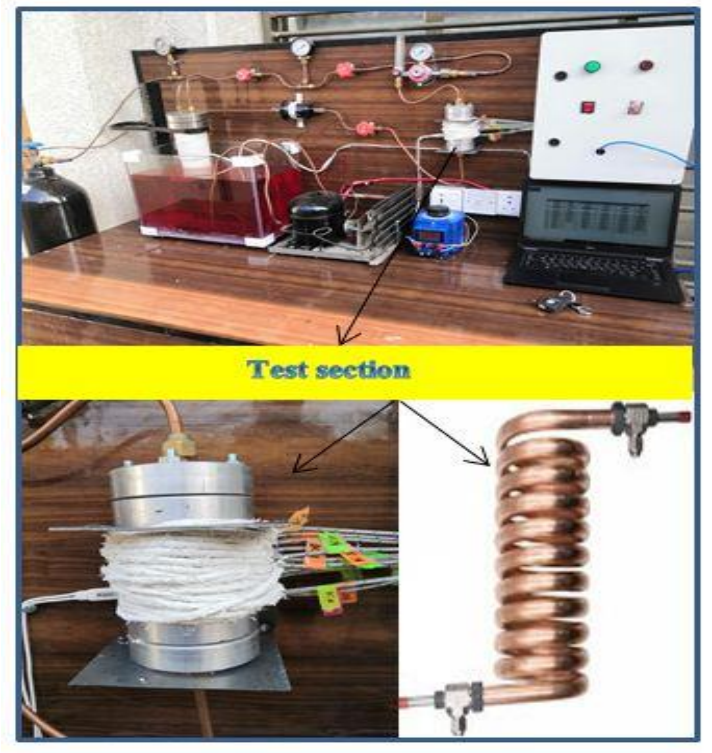

(a)

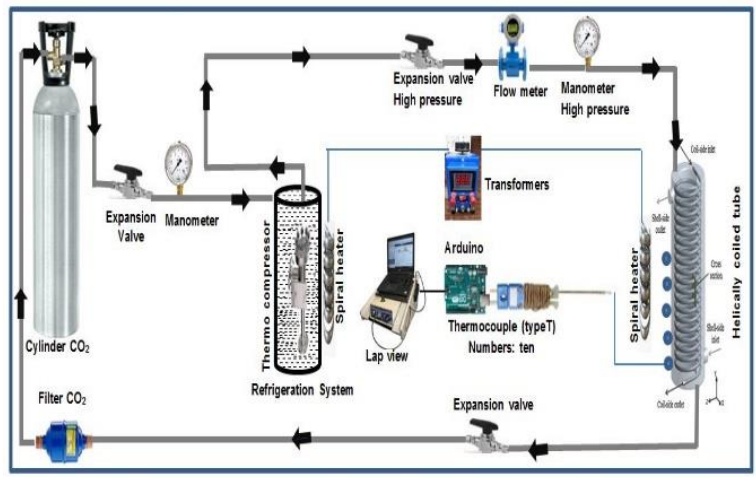

(b)

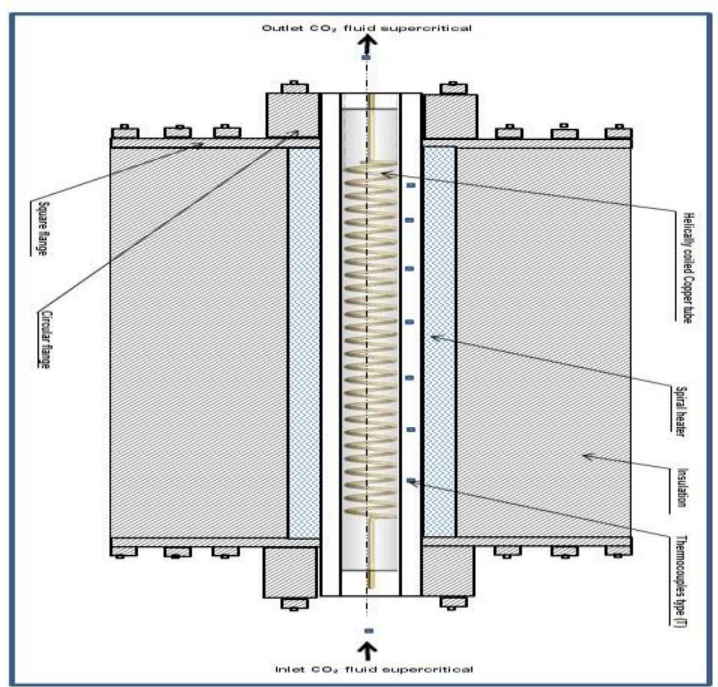

(c)

Figure 1. (a) Actual experimental work of supercritical carbon dioxide; (b) schematic experimental work of supercritical carbon dioxide; (c) schematic test section

Nusselt and Reynolds numbers for HCT heat transfer in two dimensionless can be defined by:

$$
N u=\frac{k d}{\gamma}, R e=\frac{\rho u d}{\mu}
$$

where, $\mathrm{u}$ is referring to the average velocity and $\gamma$ refers to the heat transfer average coefficients. The equation below uses to calculate the heat transfer as:

$$
\begin{gathered}
k=\frac{q}{\text { mean temperature }} \\
\text { mean temperature }=\frac{\left(T_{\text {in }}-T_{w i}\right)-\left(T_{\text {out }}-T_{w i}\right)}{\ln \left(\frac{T_{\text {in }}-T_{w i}}{T_{\text {out }}-T_{w i}}\right)}
\end{gathered}
$$

where, $T_{w i}$ means the inner wall temperature, while $T_{\text {out }, \text { in }}$ means the outside and inside temperatures. The equation below utilized to calculate the $\mathrm{CO}_{2}$ bulk temperature of $\mathrm{CO}_{2}$ as:

$$
T_{b}=\frac{T_{\text {in }}-T_{\text {out }}}{2}
$$

Eqns. (5), (6) and (7) are used to calculate the dimensionless number destruction, dimensionless exergy destruction caused by irreversibility heat transfer and dimensionless exergy destruction caused by frictional irreversibility as follows:

$$
\begin{gathered}
N_{e}=\ln \frac{1-6 S T \varphi \omega}{1-\omega-4 S T \omega \varphi}+\frac{\ln (1-6 \omega \varphi) E S}{12 S T} \\
N_{h}=\ln \frac{1-6 S T \varphi \omega}{1-\omega-4 S T \omega \varphi} \\
N_{f}=\ln \frac{1-E S(1-6 \omega \varphi S T)}{12 S T}
\end{gathered}
$$

where, ST refers to the Station number which equal to $S T=$ $\frac{N_{u}}{R_{e} P_{r}}$, ES refers to the Eskert number which equal to $S T=$ $\frac{u^{2}}{C_{p}\left(\frac{q}{h}\right)}, \varphi$ refers to the dimensionless length passage of the coil $(1 / d)$ and $\omega$ refers to the dimensionless inlet temperature ratio. Eq. (8) clears how to calculate the total pressure drop as:

$$
\begin{aligned}
& \text { pressure drop }=\text { friction pressure drop } \\
& + \text { gravitational pressure drop } \\
& + \text { acceleration pressure drop } \\
& \left(\Delta p_{f}\right)=\left(\Delta p_{m}\right)-\left(\Delta p_{g}\right)+\left(\rho_{o} g h-\Delta p_{a}\right)
\end{aligned}
$$

Eq. (10) used to calculate the Darcy friction factor is as:

$$
f_{c}=\frac{6 d \Delta p_{f} \rho_{o}}{G^{3} L}
$$

\section{RESULTS AND DISCUSSION}

Due to this paper focuses on studying the exergy destruction and heat transfer performance at pseudo-critical zone, Figure 2 presents the $\mathrm{CO}_{2}$ thermo-physical properties at $8 \mathrm{MPa}$ of pressure. $\mathrm{CO}_{2}$ thermo-physical properties consisting of $\mathrm{Cp}$ which is the specific heat, $\lambda$ which is the thermal conductivity, $\rho$ which is the fluid density and $\mu$ which is the dynamic viscosity. $\mathrm{CO}_{2}$ thermo-physical properties dramatically 
changing near the $\mathrm{T}_{\mathrm{pc}}$. It can be seen at $8 \mathrm{MPa}$ that the $\mathrm{CO}_{2}$ critical temperature was equal to $307.8 \mathrm{~K}$ approximately.

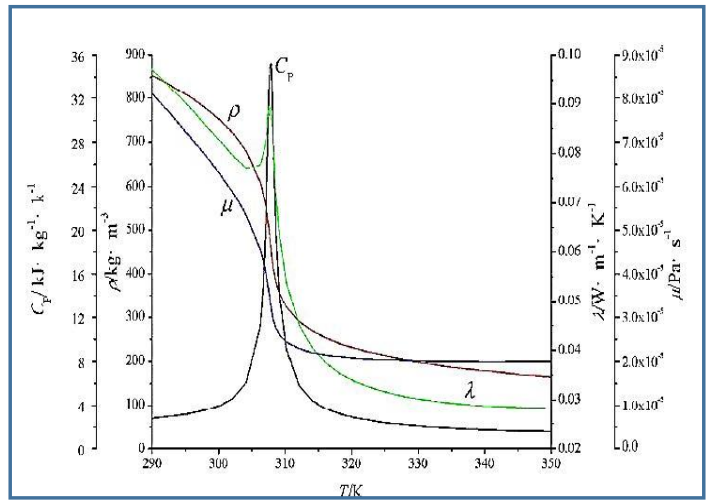

Figure 2. Thermo-physical properties of $\mathrm{CO}_{2}$ under the pressure of $8 \mathrm{MPa}$

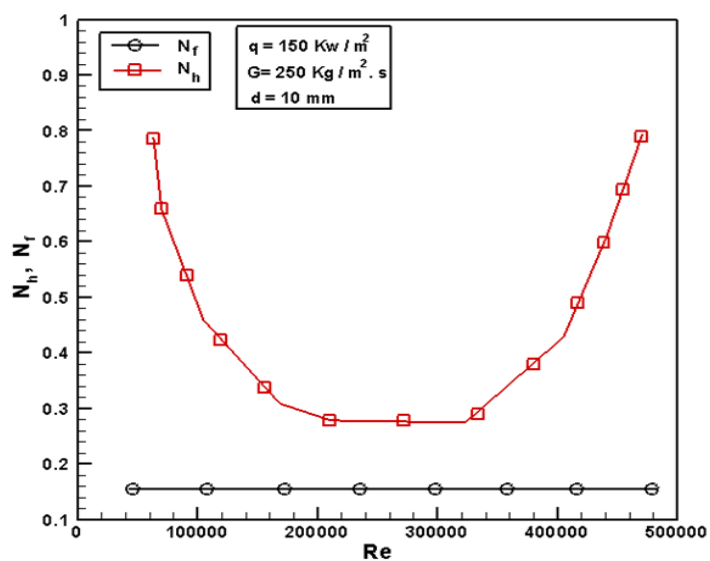

Figure 3. $\mathrm{N}_{\mathrm{h}}$ and $\mathrm{N}_{\mathrm{f}}$ performance with Re at $\mathrm{d}=10 \mathrm{~mm} \mathrm{G}=250$ $\mathrm{Kg} / \mathrm{m}^{2} . \mathrm{s}$ and $\mathrm{q}=150 \mathrm{~kW} / \mathrm{m}^{2}$

Also, it important to study the thermodynamic analysis and interfacing between $\mathrm{N}_{\mathrm{f}}$ and $\mathrm{N}_{\mathrm{h}}$ due to the irreversibilities resultant by friction and heat transfer which considering one of the important tasks for HCT. At $\mathrm{G}=250 \mathrm{Kg} / \mathrm{m}^{2}$.s and $\mathrm{q}=150$ $\mathrm{kW} / \mathrm{m}^{2}$ when the tube diameter is $10 \mathrm{~mm}$, Figure 3 presents the comparison between $\mathrm{N}_{\mathrm{f}}$ and $\mathrm{N}_{\mathrm{h}}$. the main observation in this figure was the values of $\mathrm{N}_{\mathrm{h}}$ always bigger than $\mathrm{N}_{\mathrm{f}}$ when the region in turbulent flow which was different at water and air phenomenon. The loss by irreversibility that resultant by friction factor be higher than heat transfer influence with increasing of Re. In Eq. (6) which present the ration of irreversibility distribution to illustrate the $\mathrm{N}_{\mathrm{h}}$ and $\mathrm{N}_{\mathrm{f}}$ results, it can see in flow field that the exergy destruction was mainly resulting by heat transfer irreversibility. In addition, it can neglect the effect of dimensionless exergy destruction caused by flow friction for heat transfer when the HCT be cooled. The decreasing in $\mathrm{CO}_{2}$ viscosity led to high decreasing in dimensionless exergy destruction caused by flow friction. Figure 3 also indicates at turbulent flow, curve of the $N_{h}$ arrived to the lowest value for heat transfer of HCT, and optimal Re can be obtained at lowest dimensionless exergy destruction. The biggest. value of $\mathrm{N}_{\mathrm{e}}$ was bigger than lowest $\mathrm{N}_{\mathrm{e}}$ about 45 times. This concludes that the optimal HCTs design according to the principle of dimensionless exergy destruction minimization is very important for the exergy utilization of thermal systems.
Figure 4 shows the heat fluxes variations (100-200 Kw/m) with the dimensionless exergy destruction which is considering as a function of bulk temperature when the values of $P$ and $G$ equal to $8 \mathrm{MPa}$ and $250 \mathrm{Kg} / \mathrm{m}$.s respectively. Moreover, at pseudo-critical point, the curve of $\mathrm{Ne}$ reached to the lowest value at various heat fluxes. The reason behind that was the enhancement in heat transfer at the account of the highest specific heat value. Another notice according to the irreversibility, entropy generation and exergy destruction being in the same trend of variation. The main indication can be seen in pseudo-critical region was the big difference in gaslike and liquid-like regions with different heat fluxes. Therefore, heat transfer enhancement led the value of dimensionless exergy destruction near to 0.01. In addition, increase in the heat fluxes leads to the increase of the dimensionless exergy destruction due to weak the heat transfer as a result of the big difference between bulk and wall temperatures.

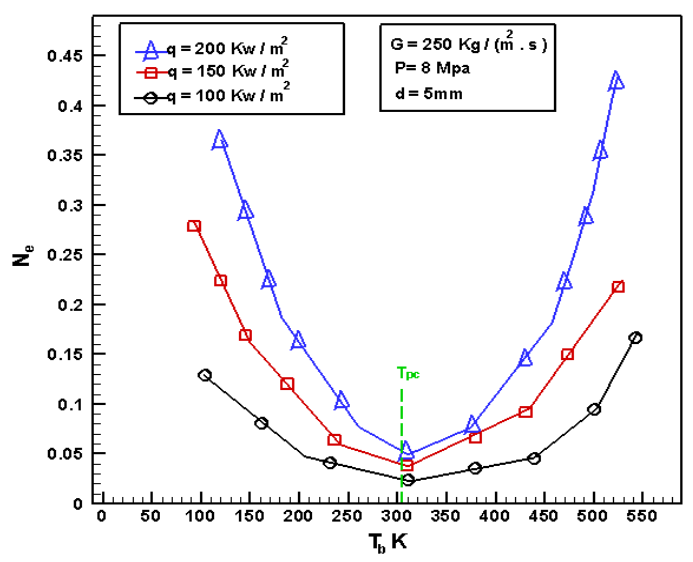

Figure 4. Dimensionless exergy destruction and temperature bulk Performance for various heat flux

The relationship between different mass fluxes (250, 500, 1000, 1500 and $2000 \mathrm{Kg} / \mathrm{m}^{2} \mathrm{~s}$ ) and dimensionless exergy destruction has presented in Figure 5 when the $q=100 \mathrm{~kW} / \mathrm{m}^{2}$ and $\mathrm{P}=8 \mathrm{MPa}$. This figure proved that the lowest dimensionless exergy destruction value was near $\mathrm{T}_{\mathrm{pc}}$. With increasing of mass flux, enhancement the heat transfer performance due to the turbulent diffusion has increased and lead to decrease the exergy destruction.

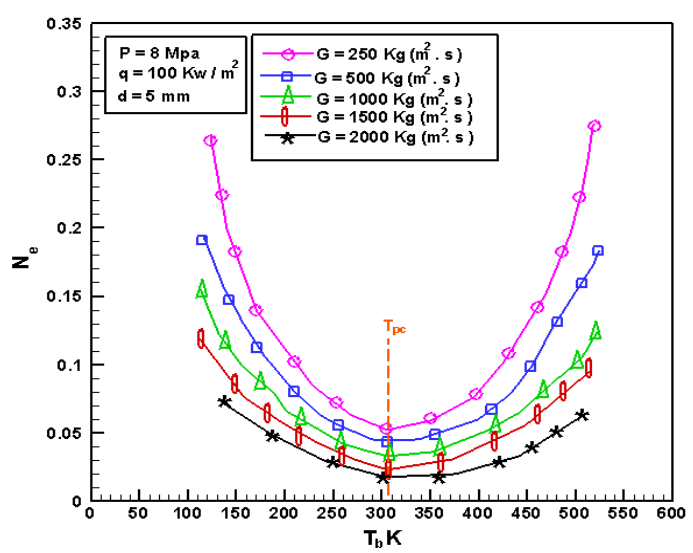

Figure 5. Dimensionless exergy destruction and temperature bulk Performance for various mass fluxes 
Figure 6 presents different pressure with different the dimensionless exergy destruction variation. The dimensionless exergy destruction increased with increasing the pressure in addition of the lower value of dimensionless exergy destruction noticed at $\mathrm{T}_{\mathrm{pc}}$. Also, bulk temperature increased at $8 \mathrm{MPa}$ to $10 \mathrm{MPa}$ of pressure range due to thermophysical properties variation. Moreover, the point above $T_{p c}$ lead to increase the pressure and decease the dimensionless exergy destruction compared with the point below $\mathrm{T}_{\mathrm{pc}}$ that be opposite behavior.

In order to obtain the optimal HCT design, this work also focused on the optimal factor of Re. At $\mathrm{G}=250 \mathrm{~kg} / \mathrm{m}^{2} . \mathrm{s}$, Figures 7 and 8 show the experimental results of $\mathrm{N}_{\mathrm{e}}$ and $\mathrm{Re}$ when the s tube diameters are 5 and $10 \mathrm{~mm}$ respectively. both of Figures proved that the optimal $\mathrm{Re}$ and lowest value of dimensionless exergy destruction which increased with heat fluxes increasing. Or, lowest $\mathrm{N}_{\mathrm{e}}$ and optimal Re depended on heat fluxes.

At $\mathrm{q}=100 \mathrm{~kW} / \mathrm{m}^{2}$ and $\mathrm{d}=5 \mathrm{~mm}$, both of Figures 9 and 10 Present mass flux effect on optimal Re. mass flux variation have been noticed with the lowest $\mathrm{N}_{\mathrm{e}}$ and optimal $\mathrm{Re}$ according to Figures 7-10, sensitivity of Re with mass flux variation was bigger than neat flux. Where, optimal $\mathrm{Re}$ increased with increasing of mass flux, while lowest $\mathrm{N}_{\mathrm{e}}$ was decreased with increasing of mass flux due to turbulent intensity.

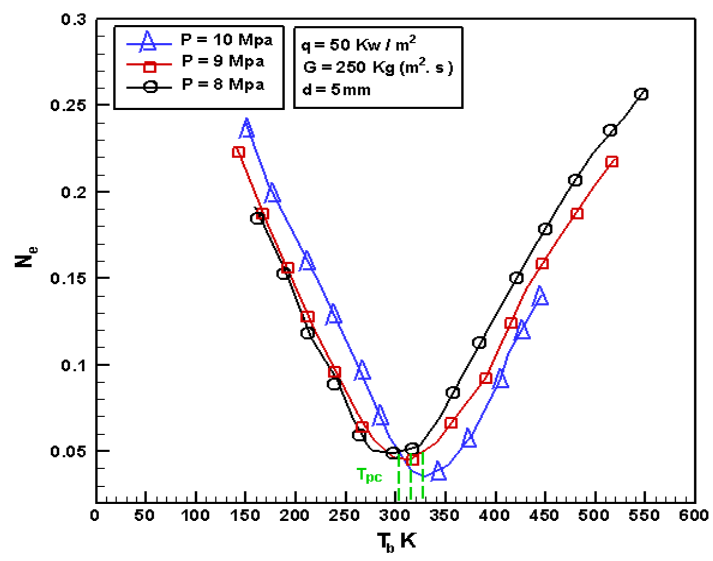

Figure 6. Dimensionless exergy destruction variation at different pressures

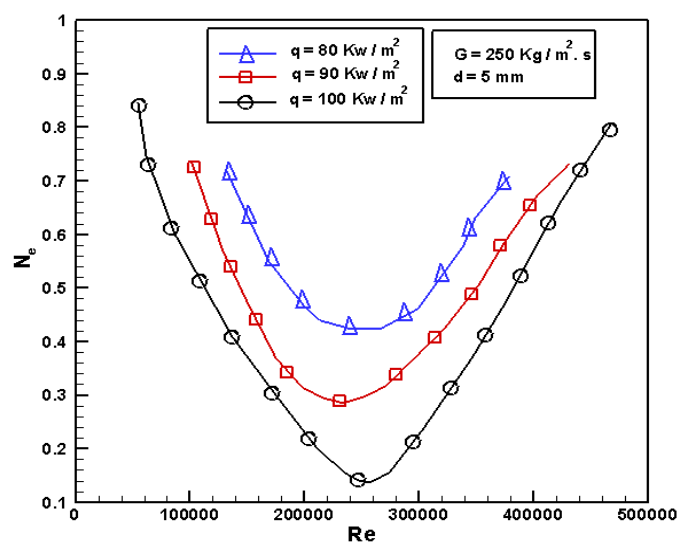

Figure 7. Dimensionless exergy destruction variation for different heat flux at $\mathrm{d}=5 \mathrm{~mm}$

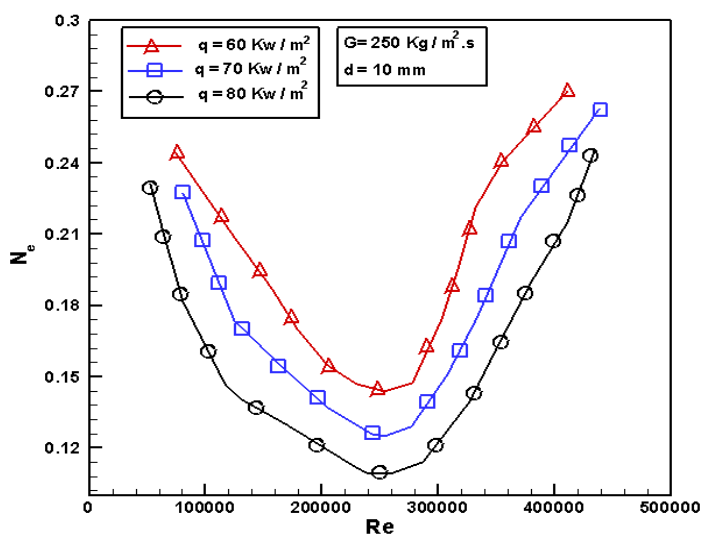

Figure 8. Dimensionless exergy destruction variation for different heat flux at $\mathrm{d}=10 \mathrm{~mm}$

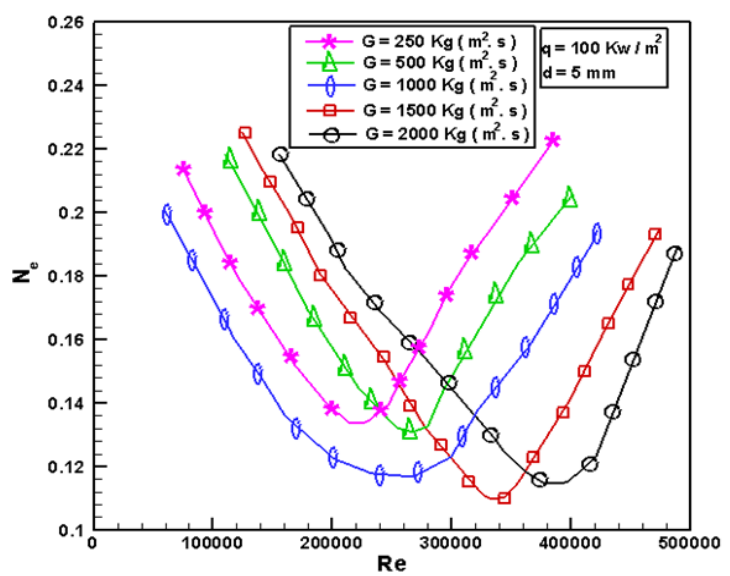

Figure 9. Dimensionless exergy destruction variation for different mass heat flux at $\mathrm{d}=5 \mathrm{~mm}$

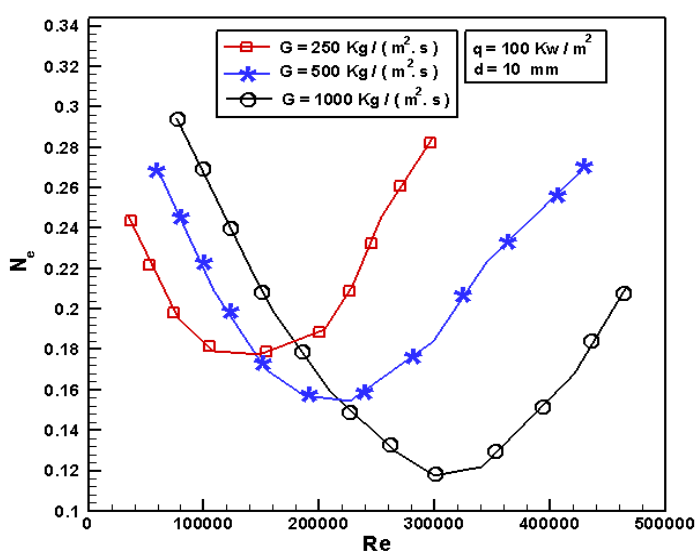

Figure 10. Dimensionless exergy destruction variation for different mass heat flux at $\mathrm{d}=10 \mathrm{~mm}$

Figure 11 shows the different $\mathrm{Ne}$ with $\mathrm{Re}$ at to diameters (5 and $10 \mathrm{~mm}$ ) when $\mathrm{G}=250 \mathrm{~kg} / \mathrm{m}^{2} . \mathrm{s}$ and $\mathrm{q}=100 \mathrm{~kW} / \mathrm{m}^{2}$. Smaller values of $\mathrm{Ne}$ have noticed in proper Re range and best exergy utilization for both diameters. dimensionless exergy destructions have increased with dimeter increasing when $\operatorname{Re}<150000$, but opposite behavior has been noticed when $\mathrm{Re}>350000$. Moreover, smallest dimensionless exergy destruction has noticed when the diameter was $5 \mathrm{~mm}$ compared with the diameter of $10 \mathrm{~mm}$. 


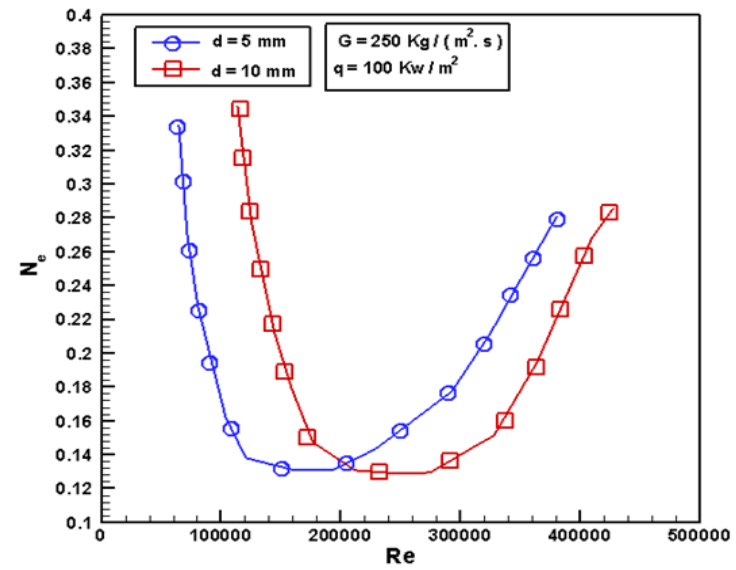

Figure 11. Re with dimensionless exergy destruction variation

According to the previous investigations, increasing of optimal Re depends on the increasing in heat flux, tube diameter and mass flux. Also, a correlation must be inferred to establish the relationship between both quantities.

$$
10^{-8} R e=1.986 \times 10^{-9} \alpha^{0.633} \beta^{-2.564} \gamma^{3.345}
$$

Correlation is an important part in the prediction of the optimal Reynolds number based on the appropriate operating condition with the parameters determined for the shape of HCT. It should take into consideration that the correlation deals with turbulent convective heat transfer in HCT when the wall heat flux is constant.

Figure 11 shows the relationship between varied heat fluxes $\left(70\right.$ to $\left.90 \mathrm{~kW} / \mathrm{m}^{2}\right)$ and pressure at $8.0 \mathrm{MPa}$. While, Figure 12 presents sing-phase water for friction pressure drop with mass fluxes. The main indication for Figure 12 was the frictional pressure drop increases with increasing of mass fluxes due to larger velocity gradient and results a shear stress for wall. When the value of heat flux equal to zero, the frictional pressure drop keep monotonically increasing with rising mass flux. The frictional pressure drop decreases firstly and then increases at $\mathrm{q}=80 \mathrm{~kW} / \mathrm{m}^{2}$. There is a small changing in frictional pressure drop between 70 and $80 \mathrm{~kW} / \mathrm{m}^{2}$.

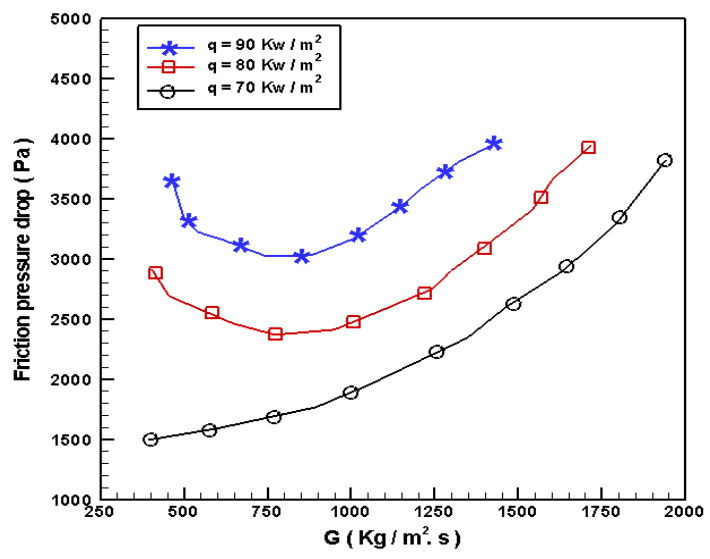

Figure 12. Mass fluxes with friction pressure drop variation

Figure 13 shows the mass flux variation from 100 to 1500 $\mathrm{kg} / \mathrm{m}^{2}$.s when the operating pressure was fixed at 8.0 MPa, while Figure 14 shows friction pressure drop variation with heat fluxes. According to Figure 14, when the heat fluxes increase, the frictional pressure drop decreases due to decreasing the viscosity with increasing of temperature which in turn decreasing the shear stress of wall in addition to physical properties variation dramatically (especially the density) near $\mathrm{T}_{\mathrm{pc}}$ which leads to decreasing the frictional pressure drop and increasing the heat fluxes. The reasons behind decreasing the density and increasing the frictional pressure drop increase are; firstly, the thermal acceleration leads to decrease the density near wall region and producing large shear stress and frictional pressure drop. Finally, difference in density throughout the test tube leads to the flow resistance by causing a secondary flow which is perpendicular to the main flow direction.

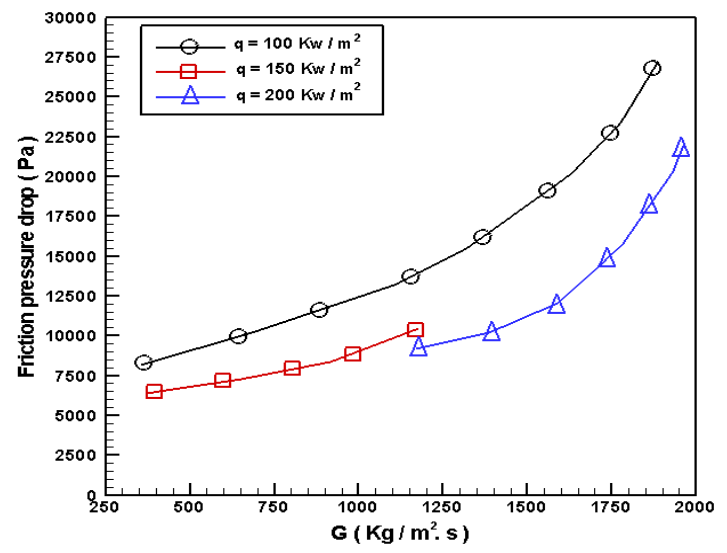

Figure 13. Mass fluxes with friction pressure drop variation for single- phase water

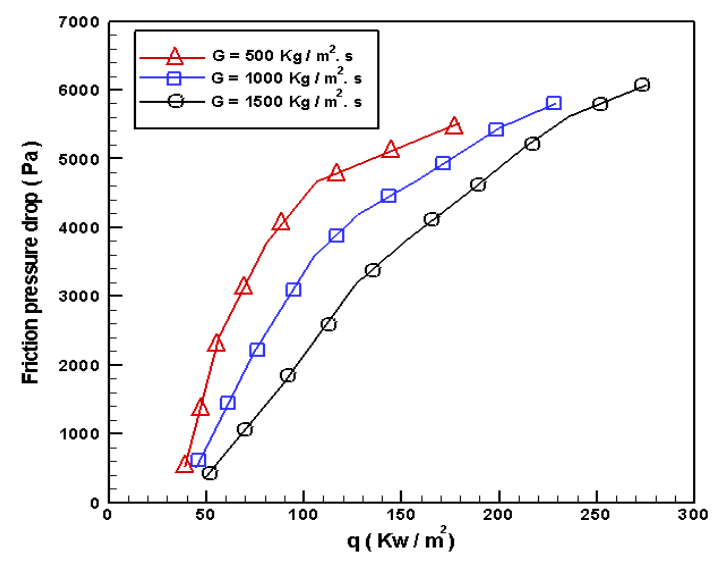

Figure 14. Heat fluxes with friction pressure drop variation for $\mathrm{CO}_{2}$

Figures 15 and 16 describes the $\mathrm{CO}_{2}$ friction factor behavior with heat fluxes for HCT. Its increased gradually with heat fluxes. friction factor has reached to the maximum value. At $\mathrm{T}_{\mathrm{pc}}$, the fluid temperature was near the wall, $\mathrm{CO}_{2}$ transferred into the supercritical liquid. The reason that led the friction factor for increasing was reduction the density that worked on the accelerate the flow and increasing the shear stress. While, the reason led the friction factor into decreasing after that was due to the fluid passing through $\mathrm{T}_{\mathrm{pc}}$.

Friction factor behavior with Re number can be seen in Figure 17 in addition to describing the Ito and white correlations. The main notice according to Figure 17 was decreasing of friction diagram with increasing of Re which is the same behavior in straight pipe case and the value was 
higher than which calculated by the two equations. Indeed, the empirical formula was depended on the flow condition. singlephase water used to obtain Ito and white correlations as a test fluid in HCT.

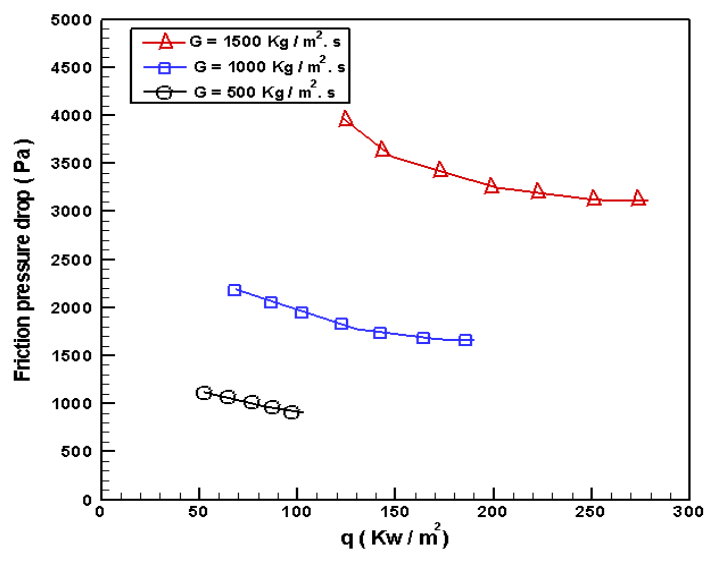

Figure 15. Heat fluxes with friction pressure drop variation for single- phase water

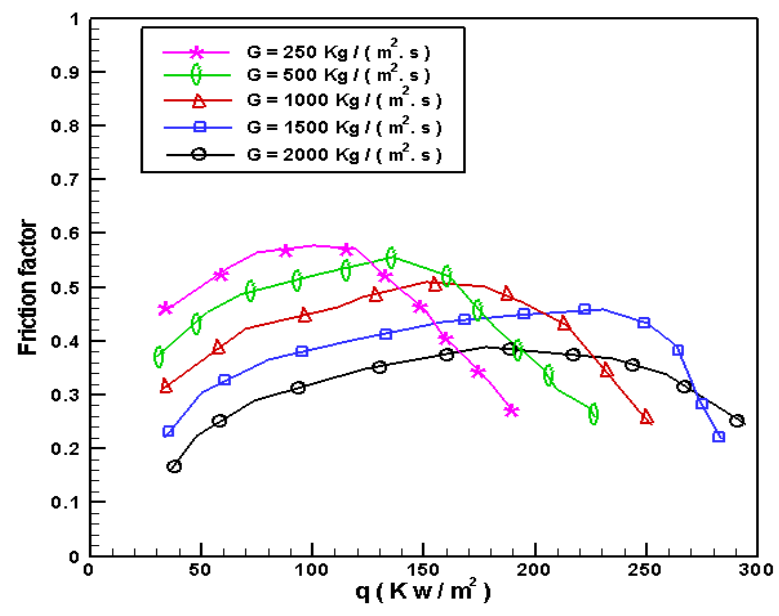

Figure 16. Friction factor variation with heat fluxes

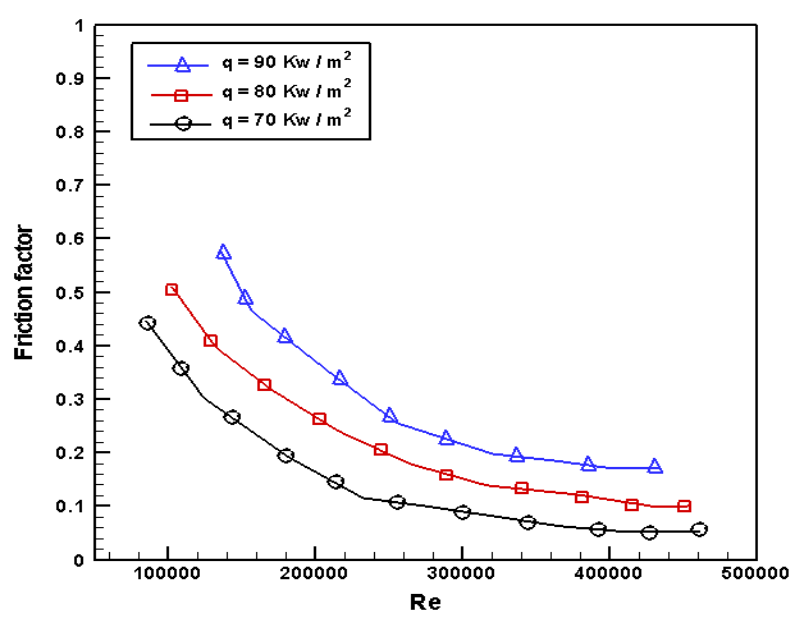

Figure 17. Friction factor variation with Re

\section{CONCLUSION}

Analysis of exergy for HCT experimentally through study the heat transfer for supercritical $\mathrm{CO}_{2}$ has been conducted in this work. Many parameters described the system behavior which are: mass and heat fluxes, tube diameters, frictional factor and frictional pressure drop. Investigation in this paper was done based on analyzing the dimensionless exergy destruction and the optimal Reynolds number influences. Based on pervious discussions. heat transfer irreversibility was led to generate the dimensionless exergy destruction which was higher than the flow friction for SC-HCT. Optimal Re and minimum dimensionless exergy destruction have been reached The tube diameter of $5 \mathrm{~mm}$ gave a smaller dimensionless exergy destruction than the tube diameter of $10 \mathrm{~mm}$ when $150000<\operatorname{Re}<350000$. Tube diameter and mass fluxes have a great effect on optimal Re more than heat fluxes. optimal $R e$ has predicted by proposed correlation in optimal operation conditions to for heat transfer in SC-HCT in order to design optimal HCT. The frictional pressure drop increased with mass fluxes firstly the decreased for supercritical $\mathrm{CO}_{2}$ with small different than single-phase water. Finally, when the mass fluxed was fixed, the frictional pressure drop decreased with the heat flux.

\section{REFERENCES}

[1] Tian, H., Chang, L., Shu, G., Shi, L. (2017). Multiobjective optimization of the carbon dioxide transcritical power cycle with various configurations for engine waste heat recovery. Energy Conversion and Management, 148: 477-488. https://doi.org/10.1016/j.enconman.2017.05.038

[2] Xu, X.X., Liu, C., Fu, X., Gao, H., Li, Y. (2015). Energy and exergy analyses of a modified combined cooling, heating, and power system using supercritical $\mathrm{CO}_{2}$. Energy, 86: 414-422. https://doi.org/10.1016/j.energy.2015.04.043

[3] Tian, H., Wu, M., Shu, G., Liu, Y., Wang, X. (2017). Experimental and theoretical study of flammability limits of hydrocarbon-CO2 mixture. International Journal of Hydrogen Energy, 42(49): 29597-29605. https://doi.org/10.1016/j.ijhydene.2017.10.053

[4] Bilalov, T.R., Zakharov, A.A., Jaddoa, A.A., Gumerov, F.M., Le Neindre, B. (2017). Treatment of different types of cotton fabrics by ammonium palmitate in a supercritical $\mathrm{CO}_{2}$ environment. The Journal of Supercritical Fluids, 130: 47-55. https://doi.org/10.1016/j.supflu.2017.07.036

[5] Gumerov, F.M., Le Neindre, B., Bilalov, T.R., Sagdeev, A.A. (2016). Regeneration of spent catalyst and impregnation of catalyst by supercritical fluid. International Journal of Analytical Mass Spectrometry and Chromatography, 4(4): 51-65. https://doi.org/10.4236/ijamsc.2016.44006

[6] Jaddoa, A.A. (2021). Convection heat transfer performance for the $\mathrm{SCF}-\mathrm{CO}_{2}$ media in mini-tube with fins experimentally. Journal of Engineering Science and Technology.

[7] Naphon, P., Wongwises, S. (2006). A review of flow and heat transfer characteristics in curved tubes. Renewable and Sustainable Energy Reviews, 10(5): 463-490. https://doi.org/10.1016/j.rser.2004.09.014

[8] Wang, S.X., Zhang, W., Xu, J.L. (2013). Experimental investigation on flow characteristics of supercritical $\mathrm{CO}_{2}$ in a helically coiled tube. In Applied Mechanics and 
Materials,

368(370):

631-635

https://doi.org/10.4028/www.scientific.net/AMM.368370.631

[9] Xu, X., Zhang, Y., Liu, C., Zhang, S., Dang, C. (2018). Experimental investigation of heat transfer of supercritical $\mathrm{CO}_{2}$ cooled in helically coiled tubes based on exergy analysis. International Journal of Refrigeration, 89:

$177-185$

https://doi.org/10.1016/j.ijrefrig.2018.03.011

[10] Launder, B.E., Sharma, B.I. (1974). Application of the energy-dissipation model of turbulence to the calculation of flow near a spinning disc. Letters in Heat and Mass Transfer, 1(2): 131-137. https://doi.org/10.1016/07351933(74)90024-4

[11] Dang, C., Hihara, E. (2004). In-tube cooling heat transfer of supercritical carbon dioxide. Part 2. Comparison of numerical calculation with different turbulence models. International Journal of Refrigeration, 27(7): 748-760.

[12] Dang, C., Hihara, E. (2004). In-tube cooling heat transfer of supercritical carbon dioxide. Part 1. Experimental measurement. International Journal of Refrigeration, 27(7): 736-747. https://doi.org/10.1016/j.ijrefrig.2004.04.018

[13] Cao, X.L., Rao, Z.H., Liao, S.M. (2011). Laminar convective heat transfer of supercritical $\mathrm{CO}_{2}$ in horizontal miniature circular and triangular tubes. Applied Thermal Engineering, 31(14-15): 2374-2384. https://doi.org/10.1016/j.applthermaleng.2011.03.038

[14] He, S., Kim, W.S., Jackson, J.D. (2008). A computational study of convective heat transfer to carbon dioxide at a pressure just above the critical value. Applied Thermal Engineering, 28(13): 1662-1675. https://doi.org/10.1016/j.applthermaleng.2007.11.001

[15] Li, M.X., Lu. J.T. (2015). Heat transfer characteristics of supercritical $\mathrm{CO}_{2} / \mathrm{R} 41$ flowing in mini-channel. CIESC Journal, 66(3): 924-931.

[16] Kravanja, G., Zajc, G., Knez, Ž., Škerget, M., Marčič, S., Knez, M.H. (2018). Heat transfer performance of $\mathrm{CO}_{2}$, ethane and their azeotropic mixture under supercritical conditions. $\quad$ Energy, 152: 190-201. https://doi.org/10.1016/j.energy.2018.03.146

[17] Cioncolini, A., Santini, L. (2006). On the laminar to turbulent flow transition in diabatic helically coiled pipe flow. Experimental Thermal and Fluid Science, 30(7): 653-661. https://doi.org/10.1016/j.expthermflusci.2006.01.004

[18] Abdel-Moneim, S.A., Ali, R.K. (2007). Performance evaluation of heat transfer enhancement for internal flow based on exergy analysis. International Journal of Exergy, 4(4): 401-420 https://doi.org/10.1504/IJEX.2007.015081

[19] Şahin, A.Z. (1998). Irreversibilities in various duct geometries with constant wall heat flux and laminar flow. Energy, 23(6): 465-473. https://doi.org/10.1016/S03605442(98)00010-3

[20] Bejan, A. (1996). Entropy generation minimization: The new thermodynamics of finite-size devices and finitetime processes. Journal of Applied Physics, 79(3): 11911218. https://doi.org/10.1063/1.362674

[21] Kkihlefa, B.J., Gaddoa, A.A., Reja, A.H. (2021). Experimental investigation of heat transfer features for vertical tube using porous media and Carbon dioxide, Journal of Mechanical Engineering Research and Developments, 44(5): 188-195.

\section{NOMENCLATURE}

$\mathrm{Nu}$
$\mathrm{Re}$
$\mathrm{u}$
$k$
$T_{w i}$
$T_{\text {out,in }}$
$T_{b}$
$N_{e}$
$N_{h}$

$N_{f}$
$\mathrm{ST}$
$\mathrm{ES}$
$\Delta P$
$\mathrm{~d}$
$\mathrm{u}$
1
$\mathrm{C}_{\mathrm{p}}$
$\mathrm{G}$
$\mathrm{q}$
$\mathrm{p}$
$\mathrm{T}$

Greek symbols

$\varphi$

$\omega$

$\alpha$

$\beta$

$\gamma$

$f$

Average coefficients of heat transfer

dimensionless ratio of Inlet and outlet temperature

Inlet temperature dimensionless ratio

Length of Dimensionless passage of the coil $(1 / \mathrm{d})$

Dimensionless duty parameter $\frac{q}{G C_{P} T_{\text {in }}}$

difference ratio of dimensionless temperature inlet friction factor

\section{Subscripts}

$\begin{array}{ll}\text { in } & \text { Inlet } \\ \text { out } & \text { Outlet } \\ \text { W } & \text { wall } \\ \text { i } & \text { inside } \\ \text { o } & \text { outside }\end{array}$

